\title{
Dark Time Matter: Dark Character Profiles and Time Perspective
}

\author{
Danilo Garcia ${ }^{1,2,3} 3^{*}$ Patricia Rosenberg1,3, Fernando Renee González Moraga ${ }^{3,4}$, \\ Max Rapp-Ricciardi ${ }^{1,2,3}$
}

\author{
${ }^{1}$ Blekinge Center of Competence, Blekinge County Council, Karlskrona, Sweden \\ ${ }^{2}$ Department of Psychology, University of Gothenburg, Gothenburg, Sweden \\ ${ }^{3}$ Network for Empowerment and Well-Being, Sweden \\ ${ }^{4}$ Barn-och ungdomshabiliteringen, Region Kronoberg, Växjö, Sweden \\ Email: *danilo.garcia@icloud.com
}

How to cite this paper: Garcia, D., Rosenberg, P., Moraga, F. R. G., \& Rapp-Ricciardi, M. (2018). Dark Time Matter: Dark Character Profiles and Time Perspective. Psychology, 9, 63-79.

https://doi.org/10.4236/psych.2018.91005

Received: December 11, 2017

Accepted: January 9, 2018

Published: January 12, 2018

Copyright (c) 2018 by authors and Scientific Research Publishing Inc. This work is licensed under the Creative Commons Attribution International License (CC BY 4.0).

http://creativecommons.org/licenses/by/4.0/

\section{cc) (i) Open Access}

\begin{abstract}
Background: Humans seem to have a unique ability to consciously organize the flow of time (i.e., past, present, and future) and to intentionally choose goals and values (i.e., character: self, others, the universe). These two parts of human awareness have implications for individuals' relation to a society that will flourish or perish. In fact, a balanced time perspective is suggested as necessary for the experience of well-being and optimal societal functioning. Nevertheless, low character development might be expressed as a Dark Triad: Machiavellianism, narcissism, and psychopathy. In the present study, we aimed to investigate if individuals differ in their outlook on time depending on their dark character profiles. Method: We re-analyzed data from a previous study in which participants $(N=338)$ responded to the Short Dark Triad Inventory and the Zimbardo Time Perspective Inventory. However, here we use the Dark Cube (Garcia, 2017a), a model of malevolent character based on Cloninger's biopsychosocial theory of personality and in the assumption of a Dark Triad, thus, clustering individuals in eight profiles (i.e., the combination of high/low in three malevolent character traits). Results: The results for each trait suggest multi-finality (i.e., same antecedents, different outcomes) and equifinality (i.e., different antecedents, same outcomes). For example, individuals high in narcissism presented a balanced time perspective when manipulative behavior was also high and psychopathy was low. Conclusions: In certain conditions, malevolent character is associated to a balanced time perspective. Thus, suggesting that in order to understand well-being and optimal societal functioning, we need to look at human awareness in relation to both time (i.e., past, present, future) and space (i.e., character: self, others, the universe).
\end{abstract}




\section{Keywords}

Character, Dark Cube, Dark Triad, Machiavellianism, Narcissism, Psychopathy, Time Perspective, Unification vs. Uniqueness Debate

" $A$ human being is a part of the whole, called by us "Universe", a part limited in time and space. He experiences himself, his thoughts and feelings as something separated from the rest-a kind of optical delusion of his consciousness. The striving to free oneself from this delusion is the one issue of true religion. Not to nourish the delusion but to try to overcome it is the way to reach the attainable measure of peace of mind."

Albert Einstein

\section{Introduction}

Human awareness includes our unique ability to consciously organize the self in different time dimensions: the past, the present, and projecting the self into the future (Gilbert, 2007). This cognitive process (Stolarski, Fieulaine, \& van Beek, 2015), which often is an unconscious process (Zimbardo \& Boyd, 1999), can be organized in five time perspective dimensions: (1) past positive, reflecting a sentimental and positive view of the past, (2) past negative, which reflects a pessimistic attitude toward the past, (3) present hedonistic, reflecting the desire of experiencing pleasure with slight concern for future consequences, (4) present fatalistic, which reflects a lack of hope and control for the future, and (5) future, which reflects the ability to find reward in achieving specific long-term goals (Zimbardo, Keough, \& Boyd, 1997; Zimbardo \& Boyd, 1999, 2008). A balanced time perspective (i.e., low past negative, high past positive, low present hedonistic, and high future; Zimbardo \& Boyd, 2008, Stolarski, Bitner, \& Zimbardo, 2011) is suggested as necessary for the experience of well-being and optimal societal functioning (Sailer, Rosenberg, Nima, Gamble, Gärling, Archer, \& Garcia, 2014; Garcia, Sailer, Nima \& Archer, 2016; Boniwell \& Zimbardo, 2004; Zimbardo \& Boyd, 1999, 2008; Stolarski, Wiberg, \& Osin, 2015; Dunkel \& Weber, 2010; Figueira \& Bártolo-Ribeiro, 2013; Drake, Duncan, Sutherland, Abernethy \& Henry, 2008; Boniwell, Osin, Linley \& Ivanchenko, 2010; Stolarski, Bitner \& Zimbardo, 2011; Vowinckel, Westerhof, Bohlmeijer, \& Webster, 2015; Webster, 2011). For instance, time perspective or the way in which individuals anchor events and experiences in time to make sense of them is predictive of their life satisfaction (Garcia, Sailer, Al Nima, \& Archer, 2016; Sailer et al., 2014), use of drugs, alcohol and tobacco (Keough, Zimbardo \& Boyd, 1999), risky driving (Zimbardo, Keough, \& Boyd, 1997), and aggression (Stolarski, Zajenkowski, \& Zajenkowska, 2016).

Additionally, human awareness has also a space dimension: character, an individual's goals and values or what she/he makes of herself/himself intentionally (Cloninger, 2004). According to Cloninger's theory of human personality, cha- 
racter is related to the person's ability for self-awareness and is ternary in nature, that is, awareness and relationship to the self, to others, and to something bigger than the self, such as, God, nature, and/or the universe (Cloninger, 2004). In short, (Cloninger, 2004) suggest that coherence in three character dimensions is essential for sustainable well-being: self-directedness (i.e., a sense of the self as autonomous, responsible, resourceful and also self-efficacy), cooperativeness (i.e., the self as tolerant, helpful, empathic, and cooperative), and self-transcendence (i.e., the self as part of something beyond the self and others) (Cloninger, 2004). In this context, Dark Triad Theory posits three malevolent character traits: Machiavellianism, narcissism, and psychopathy (Paulhus \& Williams, 2002). Individuals high in Machiavellianism are manipulative (Jones \& Paulhus, 2009), have a cynical worldview and lack morality (Christie \& Geis, 1970), individuals high in narcissism have a tremendous sense of grandiosity and need for exhibitionism but, at the same time, a vulnerable self-esteem (Morf \& Rhodewalt, 2001; Raskin R \& Hall, 1979), and individuals high in psychopathy are low in empathy, low in conscientiousness, experience low levels of anxiety, are highly impulsive, and express high levels of thrill-seeking behavior (Furnham, Richards, \& Paulhus, 2013, Hare, 1985). Hence, individuals high in any of the dark character traits have one core behavior in common: uncooperativeness (Garcia, Adrianson, Archer, \& Rosenberg, 2015; Garcia \& Rosenberg, 2016; Kajonius, Persson, Rosenberg, \& Garcia, 2016). In other words, individuals who express these malevolent character traits or the lack of a mature character (i.e., low empathy, low self-control, and low "moral intuition") might orient society towards violence (i.e., separation) and away from cooperation and altruism (i.e., unity) (cf. Pinker, 2011).

With respect to time perspective, individuals with high levels in the dark traits, especially Machiavellianism and psychopathy, should display a past negative outlook since they report having a negative parent-child relationship and family functioning (Láng \& Lénárd, 2015). Moreover, individuals with high levels in the dark traits use fast strategies in their life, such as high frequency mating with early start, and little investment in social relationships and their offspring (cf. González, Nima \& Garcia, 2017). Additionally, individuals with high levels of psychopathy show dysfunctional impulsivity and those high in narcissism display functional impulsivity, while individuals high in Machiavellianism do not show any of these types of impulsive behavior (Jones \& Paulhus, 2011). The use of fast life strategies and impulsive behavior, suggest that individuals high in the dark traits might also display a high present hedonistic time perspective. Indeed, studies using Zimbardo's Time Perspective Questionnaire, show that individuals who express dark personalities experience a negative view of the past, a more hedonistic and more fatalistic view of the present, and a less future-oriented outlook (González, Nima, \& Garcia, 2017; see also Birkás \& Csathó, 2015; Zajenkowski, Witowska, Maciantowicz, \& Malesza, 2016). More specifically, individuals high in malevolent character tend to live for the moment 
and claim for immediate rewards. Machiavellianism is positively associated with the present fatalistic dimension, probably mirroring the cynical worldview of an individual high in manipulative behavior. Moreover, psychopathy is negatively associated with the future dimension, which is in line with the impulsive and thrill-seeking behavior of an individual with high levels of psychopathy (Birkás \& Csathó, 2015). In another study, however, the past positive and future dimensions were significantly positively associated to narcissism, thus, suggesting that at least among individuals high in narcissism a malevolent character is actually associated to a sentimental and positive view of the past and the ability to find reward in achieving specific long-term goals (González, Nima, \& Garcia, 2017). That is, even a person with a malevolent character development might have a balanced time perspective.

Nevertheless, these mixed and inconsistent associations between the dark traits and the time perspective dimensions are probably a result of the inaccuracy of linear approaches to the study of personality (cf. Cloninger, 2004; Garcia \& Rosenberg, 2016; Garcia \& Lindskär, 2016; Garcia, 2017ab). Character is indeed better understood as a whole system unit or a dynamic complex adaptive system (Cloninger, 2004), that is, by analyzing patterns of information or profiles. In short, although there should be a countless of probable patterns of combinations of individuals' levels of character traits, if viewed at a global level, there should be a small number of more frequently observed patterns or profiles (Bergman \& Wångby, 2014; Bergman \& Magnusson, 1997; see also Cloninger, Svrakic, \& Svrakic, 1997, who explain nonlinear dynamics in complex adaptive systems). If the Dark Triad is composed of overlapping ternary constructs that are distinctive enough to warrant separate measurement (Paulhus \& Williams, 2002), then they are better understood as one dynamic complex adaptive system (see among others Cloninger, 2004). Indeed, the dark traits have been associated to low self-actualization, low goal-directedness, low self-acceptance, low helpfulness, low tolerance towards others, and low levels of empathy (Garcia \& Rosenberg, 2016).

In this line, Garcia (Garcia \& Rosenberg 2016; Garcia, 2017a) has presented an analogy to Cloninger's "light" character cube (Cloninger, 2004) that theorizes all eight possible combinations of high/low scores in Machiavellianism, narcissism, and psychopathy (see Figure 1). Garcia suggested the Dark Cube, with its eight dark profiles, as a tool for bringing some light on the mixed and inconsistent linear associations in the Dark Triad literature (Garcia, 2017a). For instance, although the Big Five traits (agreeableness, openness to experience, neuroticism, extraversion and conscientiousness; Costa, McCrae \& Dye, 1991) are proposed to provide a comprehensive taxonomy in the analysis of individual differences (John \& Srivastava, 1999; González, 2015), the associations between dark and Big Five traits, with the exception of agreeableness, are neither consistent or large (Vernon, Villani, Vickers \& Harris, 2008). Indeed, two studies using the Dark Cube (Garcia \& Rosenberg, 2016; Garcia \& González, 2017) suggest that malevolent 


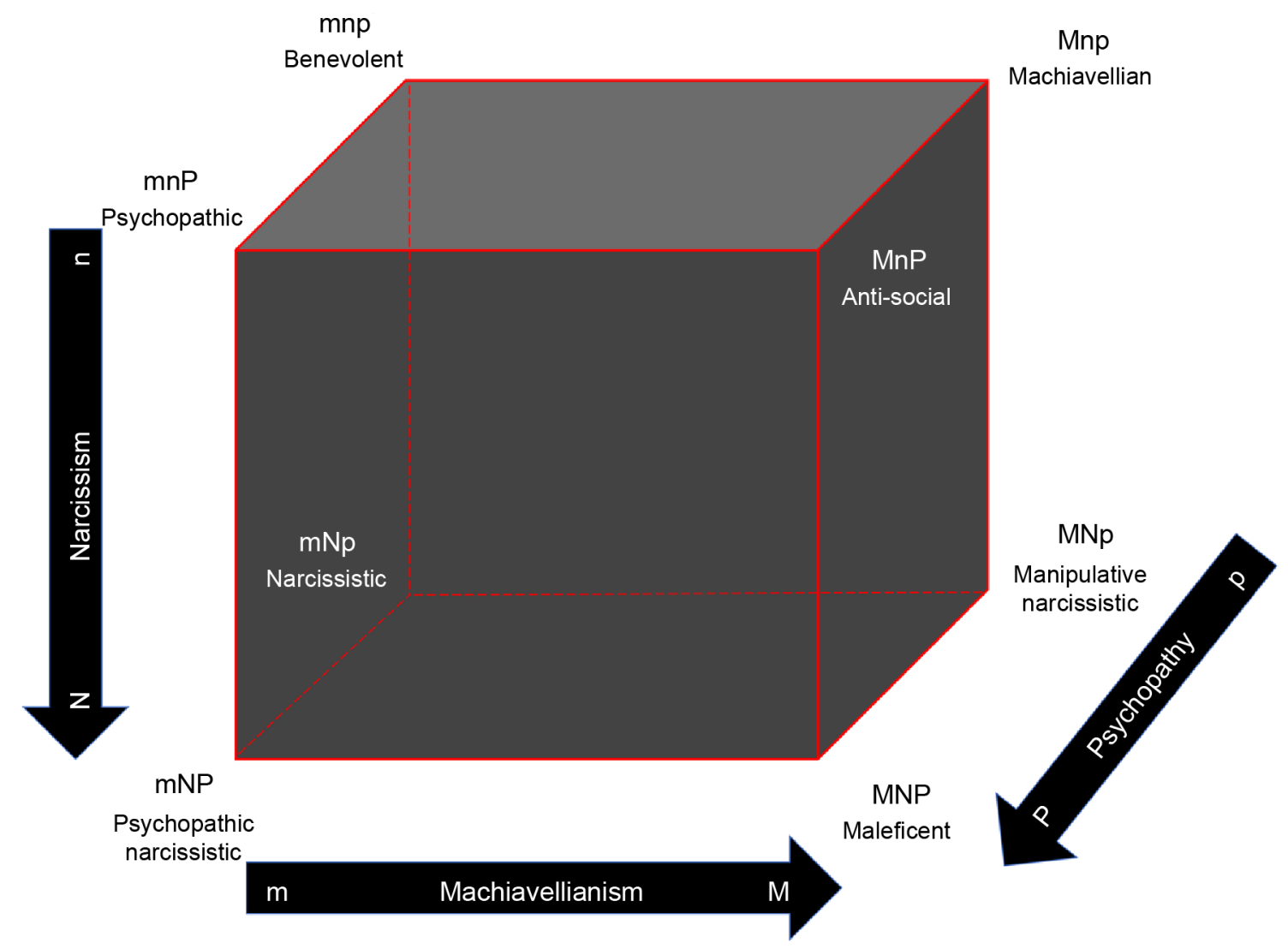

Figure 1. The Dark Cube as an analogy to Cloninger's character cube, showing all eight possible combinations of high/low scores in Machiavellianism, narcissism, and psychopathy. Note: adapted with permission from C. R. Cloninger. The directions of the arrows represent higher values. $\mathrm{M}=$ high Machiavellianism; $\mathrm{m}=$ low Machiavellianism; $\mathrm{N}=$ high narcissism; $\mathrm{n}=$ low narcissism; $\mathrm{P}=$ high psychopathy; $\mathrm{p}=$ low psychopathy. Originally published in: Garcia \& Rosenberg (2016). The dark cube: dark and light character profiles. PeerJ 4:e1675.

characters traits are associated to specific personality traits only under certain conditions. For example, while high narcissism-high extraversion and high psychopathy-low agreeableness were consistently associated across profiles, the rest of the comparisons showed a complex interaction (e.g., high Machiavellianism-high neuroticism only when both narcissism and psychopathy were low, high narcissism-high conscientiousness only when both Machiavellianism and psychopathy were also high, and high psychopathy-high neuroticism only when Machiavellianism was low and narcissism was high). We argue that Dark Triad Theory would benefit from a person-centered approach, such as the Dark Cube, which is based on a biopsychosocial model of personality (cf. Cloninger, 2004; Cloninger, Salloum, \& Mezzich, 2012), to discern the complex association between time and space dimensions of human awareness.

\section{The Present Study}

In the present study, we investigated the association between people's dark character and the five time perspective dimensions by simply comparing individuals with different profiles (i.e., matched comparisons). The present study is a 
re-analysis of the data in the study by González and colleagues (2017). Here, however, instead of using linear structural equational models, as in the original article, we used the Dark Character Cube (i.e., the combination of high/low in the three Dark Triad character traits) for the comparison of individuals who differ in one dark character trait, while holding the other two constant. This nonlinear or person-centered approach takes into account the features of complex adaptive systems, such as, multi-finality: the same malevolent character trait (i.e., same antecedents) can lead to different time perspective outlooks (i.e., different outcomes); and equifinality: different malevolent character traits (i.e., different antecedents) lead to the same time perspective outlook (i.e., same outcomes) (Cloninger, 2004; Garcia, 2017ab). In other words, or to give an example, high levels of narcissism might lead to either high levels in the present hedonistic or high levels in the past positive dimension; and high levels of either narcissism or psychopathy might both lead to high levels in the present hedonistic dimension. The question is, if any of the dark malevolent character profiles experience a balanced time perspective.

\section{Method}

\subsection{Participants and Procedure}

Participants $(N=338)$ were recruited through Amazon's Mechanical Turk ${ }^{1}$ (MTurk; http://www.mturk.com/mturk/welcome) and were informed that the survey was voluntary, anonymous, and that they could terminate the survey at any time. The MTurk workers received $\$ 0.50$ as compensation for their participation. We added two control questions to the survey, to control for automatic responses (e.g., "This is a control question, please answer "either agree or disagree"). The final sample, after taking away those who responded erroneously to one or both of the control questions ( $n=50,14.79 \%$ of all who participated), constituted 288 participants, 86 males (36.31\%) and 203 females (63.19\%), with an age mean $=34.16$ years, $\mathrm{SD}=12.49$.

\subsection{Instruments}

\subsubsection{The Short Dark Triad Inventory (Jones \& Paulhus, 2014)}

This instrument comprises 27 items, 9 per each dark trait. The items were rated on a 5-point Likert scale $(1=$ strongly disagree, $5=$ strongly agree $)$. Examples of the items are: "Most people can be manipulated" (Machiavellianism, $\alpha=.78$ ), "People see me as a natural leader" (narcissism; $\alpha=.71$ ), and "Payback needs to be quick and nasty" (psychopathy; $\alpha=.70$ ).

\subsubsection{The Zimbardo Time Perspective Inventory (Zimbardo \& Boyd, 1999)}

This instrument consists of 56 items that measure the following five time dimensions: Past Positive (e.g., "It gives me pleasure to think about my past"; $\alpha=.81$ ),

${ }^{1}$ For validation of MTurk as a data collection tool see among others: Rand, 2011; Buhrmeister, Kwang \& Gosling, 2011. 
Past Negative (e.g., "I think about the good things that I have missed out on in my life"; $\alpha=.82$ ), Present Hedonistic (e.g., "Taking risks keeps my life from becoming boring"; $\alpha=.80$ ), Present Fatalistic (e.g., "Fate determines much in my life"; $\alpha=.71$ ), and Future (e.g., "I believe that a person's day should be planned ahead each morning"; $\alpha=.76$ ). The items were rated on a 5-point Likert scale $(1=$ very untrue, 5 = very true $)$.

\section{Results}

\subsection{Statistical Procedure}

The sample was divided into subjects above (high) and below (low) the median for each of the three dark traits: Machiavellianism (median $=3.00$; $\mathrm{M}$ for high, $\mathrm{m}$ for low), narcissism (median $=2.78$; $\mathrm{N}$ for high, $\mathrm{n}$ for low), and psychopathy (median $=1.78 ; \mathrm{P}$ for high, $\mathrm{p}$ for low). Then the participants were grouped according to all the possible combinations of high and low dark trait scores to define the eight possible Dark Triad profiles: MNP "maleficent" $(n=70,24.6 \%)$, MNp "manipulative narcissistic" $(n=22,7.7 \%), \mathrm{MnP}$ "anti-social” $(n=36$, 12.6\%), Mnp "Machiavellian" ( $n=17,6.0 \%), \mathrm{mNP}$ "psychopathic narcissistic" $(n=27,9.5 \%), \mathrm{mNp}$ "narcissistic" $(n=29,10.2 \%), \mathrm{mnP}$ "psychopathic" $(n=19$, $6.7 \%)$, and mnp "benevolent" ( $n=65,22.8 \%)$.

\subsection{Linear Analyses}

Table 1 shows the linear correlations between the dark character traits and the time perspective dimensions. Machiavellianism showed positive relations with past negative, present hedonistic, and present fatalistic dimensions. Narcissism, was also positively associated to past positive and present hedonistic dimensions, while psychopathy was negatively associated to past positive and future, but positive to past negative, present hedonistic and present fatalistic dimensions.

Table 1. Correlations, means, standard deviations (sd.), and Cronbach's $\alpha$ for Dark Triad traits and time perspective dimensions.

\begin{tabular}{|c|c|c|c|c|c|c|c|c|}
\hline & \multicolumn{4}{|c|}{ DARK TRIAD } & \multicolumn{4}{|c|}{ TIME PERSPECTIVE } \\
\hline & M & $\mathrm{N}$ & $\mathrm{P}$ & PP & $\mathrm{PN}$ & $\mathrm{PH}$ & $\mathrm{PF}$ & $\mathrm{F}$ \\
\hline \multicolumn{9}{|l|}{ Machiavellianism (M) } \\
\hline Narcissism (N) & $.37^{* * *}$ & & & & & & & \\
\hline Psychopathy (P) & $.52^{* * *}$ & $.36^{* *}$ & & & & & & \\
\hline Past Positive (PP) & -.08 & $.18^{*}$ & $-.21^{* * *}$ & & & & & \\
\hline Past Negative (PN) & $.30^{* * *}$ & -.07 & $.28^{* * *}$ & $-.35^{* * *}$ & & & & \\
\hline Present Hedonistic $(\mathrm{PH})$ & $.23^{* * *}$ & $.38^{* * *}$ & $.39^{* * *}$ & $.14^{*}$ & $.22^{* * *}$ & & & \\
\hline Present Fatalistic (PF) & $.35^{* * *}$ & .07 & $.39^{* * * *}$ & -.10 & $.41^{* * *}$ & $.37^{* * *}$ & & \\
\hline Future (F) & -.09 & .11 & $-.31^{* * *}$ & $.25^{* * *}$ & $-.13^{*}$ & $-.25^{* * *}$ & $-.33^{* * *}$ & \\
\hline Mean and $S d .( \pm)$ & $3.00 \pm .71$ & $2.74 \pm .65$ & $1.84 \pm .58$ & $3.44 \pm .76$ & $3.18 \pm .78$ & $3.13 \pm .61$ & $2.45 \pm .64$ & $3.62 \pm .56$ \\
\hline Cronbach's $\alpha$ & .78 & .71 & .70 & .81 & .82 & .80 & .71 & .76 \\
\hline
\end{tabular}

Note: Black cells mark significant correlations between dark traits and time perspective dimensions. 


\subsection{Non-Linear Analyses}

We performed paired t-tests to evaluate the non-linear influence of each of the Dark Triad profiles on the five time perspective dimensions (cf. Cloninger \& Zohar, 2011; Garcia \& Rosenberg, 2016; Garcia \& González, 2017). That is, these comparisons investigated the effect of extremes of each Dark Triad profile when the other two were held constant. In contrast to the correlation analyses, these results showed a complex interaction between dark character and time dimensions (see Table 2 for the details). For example, the relationship high Machiavellianism-high Present Fatalistic was significant only when both narcissism and psychopathy were also high (MNP vs. mNP), high narcissism-high Future only when Machiavellianism was high and psychopathy was low (MNp vs. Mnp), and high psychopathy-high Past Negative only when Machiavellianism was low and narcissism was high (mNP vs. $\mathrm{mNp}$ ).

\section{Discussion}

Humans seem to have a unique ability to consciously organize the flow of time (i.e., past, present, and future) and to intentionally choose goals and values (i.e., character). These two parts of human awareness have implications for individuals' relation to a society that will flourish or perish. In fact, a balanced time perspective is suggested as necessary for the experience of well-being and optimal

Table 2. Results from the t-tests analyses for each Dark Triad character trait for time perspective dimensions. The black cells indicate significant results.

\begin{tabular}{|c|c|c|c|c|c|c|c|c|c|c|c|c|c|c|c|c|}
\hline \multicolumn{2}{|c|}{ Dark Triad } & \multicolumn{15}{|c|}{ Time Perspective } \\
\hline \multirow{2}{*}{$\begin{array}{l}\text { Dark } \\
\text { Trait }\end{array}$} & \multirow{2}{*}{$\begin{array}{c}\text { Dark } \\
\text { Profile }\end{array}$} & \multicolumn{3}{|c|}{ Past Positive } & \multicolumn{3}{|c|}{ Past Negative } & \multicolumn{3}{|c|}{ Present Hedonistic } & \multicolumn{3}{|c|}{ Present Fatalistic } & \multicolumn{3}{|c|}{ Future } \\
\hline & & $t$ & $p$ & $d$ & $t$ & $p$ & $d$ & $t$ & $p$ & $d$ & $t$ & $p$ & $d$ & $t$ & $p$ & $d$ \\
\hline \multirow{4}{*}{ M } & MNP vs. mNP & -1.48 & .140 & -.33 & .48 & .632 & .12 & 1.53 & .128 & .36 & 3.50 & $<.001$ & -.77 & -.71 & .476 & -.16 \\
\hline & $\mathrm{MNp}$ vs. $\mathrm{mNp}$ & .48 & .629 & .14 & 1.45 & .152 & .38 & -.09 & .923 & -.03 & .18 & .855 & .04 & 1.17 & .245 & .34 \\
\hline & $\mathrm{MnP}$ vs. $\mathrm{mnP}$ & .34 & .730 & .09 & 1.26 & .213 & .38 & .33 & .738 & .10 & 1.84 & .071 & .51 & -.17 & .862 & -.05 \\
\hline & Mnp vs. mnp & -2.03 & $<.05$ & -.51 & 2.58 & $<.05$ & 0.91 & -1.11 & .267 & -.26 & 1.61 & .111 & .50 & -.67 & .501 & -.16 \\
\hline \multirow{4}{*}{$\mathrm{N}$} & MNP vs. MnP & 1.78 & .078 & .39 & -1.95 & .053 & -.45 & 3.29 & $<.001$ & .72 & .69 & .489 & .14 & 1.15 & .252 & .27 \\
\hline & MNp vs. Mnp & 2.71 & $<.01$ & .96 & -2.14 & $<.05$ & -.65 & 2.63 & $<.05$ & 1.03 & -.76 & .450 & -.21 & 2.04 & $<.05$ & .82 \\
\hline & mNP vs. mnP & 2.90 & $<.01$ & .96 & -.15 & .881 & -.05 & 1.35 & .184 & .44 & -.23 & .818 & -.09 & 1.21 & .232 & .40 \\
\hline & $\mathrm{mNp}$ vs. $\mathrm{mnp}$ & .81 & .420 & .18 & -1.06 & .290 & -.29 & 2.53 & $<.05$ & .54 & .32 & .746 & .07 & .90 & .369 & .23 \\
\hline \multirow{4}{*}{$\mathrm{P}$} & MNP vs. MNp & -2.52 & $<.05$ & -.59 & 1.90 & .061 & .50 & 2.98 & $<.01$ & .70 & 3.02 & $<.01$ & .76 & -4.09 & $<.001$ & -1.00 \\
\hline & $\mathrm{MnP}$ vs. Mnp & -.58 & .559 & -.16 & .30 & .759 & .09 & 2.30 & $<.05$ & .67 & 1.39 & .170 & .37 & -1.13 & .260 & -.34 \\
\hline & $\mathrm{mNP}$ vs. $\mathrm{mNp}$ & -.63 & .527 & -.17 & 2.82 & $<.01$ & .73 & 1.11 & .270 & .29 & .39 & .697 & .12 & -1.97 & .053 & -.56 \\
\hline & $\mathrm{mnP}$ vs. $\mathrm{mnp}$ & -3.35 & $<.001$ & -.76 & 1.55 & .125 & .39 & 1.39 & .166 & .29 & .87 & .386 & .19 & -2.02 & $<.05$ & -.57 \\
\hline
\end{tabular}

Note: $d=$ Cohen's $d . \mathrm{M}=$ high Machiavellianism; $\mathrm{m}=$ low Machiavellianism; $\mathrm{N}=$ high narcissism; $\mathrm{n}=$ low narcissism; $\mathrm{P}=$ high psychopathy; $\mathrm{p}=$ low psychopathy. MNP "maleficent", MNp "manipulative narcissistic", MnP "anti-social”, Mnp "Machiavellian", mNP "psychopathic narcissistic", mNp "narcissistic", mnP "psychopathic", and mnp "benevolent". 
societal functioning (cf. Sailer et al., 2014; Garcia, Sailer, Nima \& Archer, 2016; Boniwell \& Zimbardo, 2004; Zimbardo \& Boyd, 1999, 2008; Stolarski, Wiberg, \& Osin, 2015; Dunkel \& Weber, 2010; Figueira \& Bártolo-Ribeiro, 2013). In the present study, we aimed to investigate if individuals differ in their perspective of time depending on their dark character profiles. As the backdrop of our investigation, we used the Dark Cube (Garcia, 2017a), a model of malevolent character based on Cloninger's biopsychosocial theory of personality and in the assumption of a Dark Triad. We expected that, in certain conditions, malevolent character could be associated to a balanced time perspective, that is, having a sentimental and positive view of the past, rather than a pessimistic attitude toward the past, and having the ability to find reward in achieving specific long-term goals. While the linear analyses (i.e., correlations) mainly replicated earlier studies (e.g., González, Nima \& Garcia, 2017; see also Birkás \& Csathó, 2015; Zajenkowski, Witowska, Maciantowicz, \& Malesza, 2016), the nonlinear analyses using the Dark Cube profiles showed the properties of complex adaptive systems: multi-finality (i.e., same antecedents, different outcomes) and equifinality (i.e., different antecedents, same outcomes) (cf. Cloninger, 2004).

High levels of Machiavellianism were associated to low levels of past positive and high levels of past negative only when narcissism and psychopathy were low (Mnp vs. mnp). Moreover, Machiavellianism was associated to high levels of present fatalistic only when narcissism and psychopathy were also high (MNP vs. mNP). Hence, under certain conditions, individuals high in Machiavellianism have a constant sense of negativity about their past experiences (i.e., low past positive and high past negative when narcissism and psychopathy are low) and under other conditions a view of the future as senseless and catastrophic (i.e., high present fatalistic when narcissism and psychopathy are high). Previous studies using linear methods show similar results with regard to the present fatalistic dimension (González, Nima, \& Garcia, 2017, Birkás \& Csathó, 2015). Our results, however, suggest that only the "Maleficent" profile (MNP) was associated to high levels in the present fatalistic time perspective dimension and that only the "Machiavellian" profile (Mnp) was associated to high levels in the past negative and low levels in the past positive time perspective dimensions. Furthermore, this last association ("Machiavellian" and low levels in past positive) has not been present in previous studies, not even when the same data was analyzed in the original study using structural equational models (González, Nima, \& Garcia, 2017) or using correlation analyses in the present study. In sum, individuals with the same antecedents (i.e., high levels of Machiavellianism) have different ways of organizing the flow of time. Some reminisce a dark past when they not see themselves as better than others and they do not have feelings of grandiosity (i.e., high narcissism) and when they, at the same time, do not have psychopathic tendencies. Yet other individuals with high levels of Machiavellianism see that the future happens independent of their own deeds (i.e., high present fatalistic and low future), when they are high in both narcissism and 
psychopathy. In other words, the same antecedents lead to different outcomes (i.e., multi-finality).

Narcissism was associated to high levels of present hedonistic when Machiavellianism and psychopathy were also high (MNP vs. MnP), when Machiavellianism was high and psychopathy was low (MNp vs. Mnp), and when both Machiavellianism and psychopathy were low ( $\mathrm{mNp}$ vs. mnp). High levels of narcissism were associated to high levels of past positive, low levels of past negative, high levels of present hedonistic, and high levels of future when Machiavellianism was also high and psychopathy was low (MNp vs. Mnp). In other words, individuals high in narcissism present a balanced time perspective when manipulative behavior is also high and psychopathy is low. Which, at some level, makes sense because narcissism has been associated with self-directed behavior (Garcia \& Rosenberg, 2016), which in turn leads to high well-being (Cloninger \& Zohar, 2011). Nevertheless, individuals high in narcissism score high in social desirability (Kowalski, Rogoza, Vernon, \& Schermer, 2018). Hence, our results need to be interpreted with caution. Narcissism was also associated to high past positive when psychopathy was high and Machiavellianism was low (mNP vs. mnP). Previous linear studies show the same results with regard to the present hedonistic dimension (Birkás \& Csathó, 2015), but our study shows that this might be true only under certain conditions. In sum, individuals with a "Manipulative narcissistic" ( $\mathrm{MNp}$ ) profile expressed a more balanced time perspective when compared to those with a "Machiavellian" profile (Mnp). However, due to the nature of the profile (cf. Garcia \& Rosenberg, 2016), we suggest that this is a balanced time perspective that is person-centered and manipulative, thus, probably orienting society towards violence (i.e., separation) and away from cooperation and altruism (i.e., unity) (cf. Pinker, 2011). As in the results around Machiavellianism, the results around narcissism show multi-finality (i.e., same antecedents, different outcomes), but also equifinality (i.e., different antecedents, same outcomes) with regard to the organization of the flow of time. For example, high levels of narcissism lead to a nostalgic and positive view of the past (i.e., high past positive) without any association to any other time perspective when the individual is low in manipulative tendencies and high in psychopathic behavior (mNP vs. $\mathrm{mnP}$ ), but also when Machiavellianism was also high and psychopathy was low (MNp vs. Mnp).

Psychopathy was associated to low past positive, high present hedonistic, high present fatalistic, and low future when both Machiavellianism and narcissism were high (MNP vs. MNp). In addition, psychopathy was also associated to high present hedonistic when Machiavellianism was high and narcissism was low (MnP vs. Mnp), to high past negative only when Machiavellianism was low and narcissism was high (mNP vs. $\mathrm{mNp}$ ), and to low past positive and low future when Machiavellianism and narcissism were low (mnP vs. mnp) Earlier studies using linear regressions have not found the negative association between psychopathy and the past positive time perspective dimension showed here (Birkás 
\& Csathó, 2015). Again, our results here show how high levels of one malevolent character, in this case psychopathy, are associated with different ways of organizing the flow of time depending on the combination of the other two dark traits, in this case Machiavellianism and narcissism. For instance, high levels of psychopathy were associated to a less nostalgic and positive view of the past (i.e., low past positive) only when Machiavellianism and narcissism were both either low or high at the same time ( $\mathrm{MNP}$ vs. $\mathrm{MNp}$ and $\mathrm{mnP}$ vs. mnp), but associated to the past negative time perspective dimension only when Machiavellianism was low and narcissism was high ( $\mathrm{mNP}$ vs. $\mathrm{mNp}$ ), in other words, showing again both multi-finality and equifinality.

\subsection{Limitations and Future Research}

The main limitations of our study are the fact that it was cross-sectional and that the data is self-reported, therefore subject to personal perceptual bias. We recommend that replication studies and longitudinal studies should be the next step. In addition, future studies should be conducted by controlling for demographics, such as, education, age, and gender. It is also plausible to argue that dichotomizing into groups that are classified as being low or high on traits will likely cause loss of power that is equivalent to the loss in sample size (e.g., MacCallum, Zhang, Preacher, \& Rucker, 2002). For instance, some of the profiles in the present study contained a relatively low number of individuals, which might lead subsequent analyses to be less likely to find support for the hypotheses (i.e., Type II errors; Humphreys, 1978; Lagakos, 1988). Thus, the present results need to be replicated using large enough sample sizes. However, the reader should have in mind that, despite median splits making our analyses more conservative, we found significant differences in our sample. That being said, since median splits distort the meaning of high and low, it is plausible to criticize the validity of this approach to create the profiles-scores just-above and just-below the median become high and low by arbitrariness, not by reality (Garcia, MacDonald, \& Archer, 2015). That is, there still is a risk that dichotomizing the dark traits might have led to spurious main effects (cf. MacCallum, Zhang, Preacher \& Rucker, 2002). Nevertheless, there is recent evidence of the statistical robustness and valid use of median splits (Iacobucci, Posavac, Kardes, Schneider, \& Popovich, 2015ab) and also evidence of median splits being as reliable as cluster methods (Garcia, MacDonald, \& Archer, 2015). In short, although there is a risk for misleading results when using median splits, stating that median splits produce inferior analytic conclusions is a simplification and misconception of the real issue (Iacobucci, Posavac, Kardes, Schneider, \& Popovich, 2015ab).

Finally, an important venue is to test interventions that focus on time perspective change (e.g., time perspective therapy; Zimbardo, Sword, \& Sword, 2012) and see if that leads to changes in malevolent character. For example, the associations found in the present study would suggest that increases in a positive view of the past would lead to decreases in manipulative (i.e., Mnp vs. mnp) and psy- 
chopathic (i.e., MNP vs. MNp and $\mathrm{mnP}$ vs. $\mathrm{mnp}$ ) behavior. That being said, a positive view of the past was also associated to high levels of narcissism under certain conditions (i.e., $\mathrm{MNp}$ vs. $\mathrm{Mnp}$ and $\mathrm{mNP}$ vs. $\mathrm{mnP}$ ), thus, interventions need to target the view of the self in time (i.e., past, present, future) also in relation to where individuals place themselves in space. Indeed, human awareness has probably developed around the self, others, and something greater that the self, such as, God, nature or the universe as a whole (see Cloninger, 2004). In other words, humans can place their awareness on how they view themselves, their relationship with others and society, or/and their existence as a whole. So, in order for a balanced time perspective to become a useful predictive tool of a person's contribution to the development of a positive society, we also need to know the place in which her/his awareness is: the self, others and/or something spiritual. This ternary awareness of the self (i.e., the self, others and/or something greater that the self) is also a whole system unit. The understanding of human awareness in time and space might have important ramifications. For example, awareness of the self around a balanced time perspective is denoted as important for well-being (e.g., Zimbardo \& Boyd, 1999; Sailer et al., 2014; Garcia, Sailer, Nima, \& Archer, 2016), but if it is in the space of a self-centered and manipulative character profile (MNP), then it might lead to uncooperative behavior, which is definitely a bad foundation for a good society.

\subsection{Concluding Remarks}

The present investigation gives a nonlinear approach to the study of Dark Triad traits and different psychological phenomena; in this case time perspective or the way people organize the flow of time. We propose that Dark Triad Theory can benefit from nonlinear approaches, such as, the Dark Cube for the explanation of the mixed and inconsistent associations between the dark traits and time perspective dimensions, because human character is a complex dynamic adaptive system (Cloninger, 2004; cf. Garcia, 2017a). As shown, this approach denotes the importance of seeing personality a whole system unit (cf. Cloninger, 2004). As such, malevolent character expresses the characteristics of multi-finality and equifinality. That being said, previous studies suggest that the dark triad is rather a dyad, with an antisocial and manipulative factor and a narcissistic factor (e.g., Garcia \& Rosenberg, 2016, Kajonius, Persson, Garcia, \& Rosenberg, 2016; Persson, Kajonius, \& Garcia, 2016). Others have also pointed out that darkness is just the absence of light, and that we probably need to investigate the lack or underdevelopment of light character traits in order to understand what makes societies flourish or perish (Garcia \& Rosenberg, 2016; cf. Cloninger, 2004). We suggest that the Dark Character Cube is a useful tool in the investigation of a consistent Dark Triad Theory (cf. Garcia \& Rosenberg, 2016; Garcia \& González, 2017; Garcia, 2017a). Whatever the case, the role of a balanced time perspective might need to be mapped in a theory of human awareness in time and space. The cultivation of positive aspects of human character, for instance, 
especially self-transcendence, might play an important role in the future well-being of humanity because that will further develop the extent to which we are self-aware of our participation in a universal unity of being and our ability to be healthy, happy, and fulfilled in the face of current world challenges (Cloninger, 2004, 2006, 2007, 2013; Garcia, Moradi, Amato, Granjard, \& Cloninger, 2017).

"My courtiers called me the Happy Prince, and happy indeed I was, if pleasure be happiness. So I lived, and so I died. And now that I am dead they have set me up here so high that I can see all the ugliness and all the misery of my city, and though my heart is made of lead yet I cannot choose but weep."

From “ The Happy Prince” by Oscar Wilde

\section{Acknowledgements}

The development of this article was funded by a grant from the Swedish Research Council (Dnr. 2015-01229). The funders had no role in study design, data collection and analysis, decision to publish, or preparation of the manuscript.

\section{References}

Bergman, L. R., \& Magnusson, D. (1997). A Person-Oriented Approach in Research on Developmental Psychopathology. Development and Psychopathology, 9, 291-319.

Bergman, L. R., \& Wångby, M. (2014). The Person-Oriented Approach: A Short Theoretical and Practical Guide. Eesti Haridusteaduste Ajakiri, 2, 29-49.

Birkás, B., \& Csathó, Á. (2015). Size the Day: The Time Perspectives of the Dark Triad. Personality and Individual Differences, 86, 318-320. https://doi.org/10.1016/j.paid.2015.06.035

Boniwell, I., \& Zimbardo, P. (2004). Balancing Time Perspective in Pursuit of Optimal Functioning. In P. A. Linley, \& S. Joseph (Eds.), Positive Psychology in Practice (pp. 165-179). Hoboken, NJ: Wiley. https://doi.org/10.1002/9780470939338.ch10

Boniwell, I., Osin, E., Linley, P. A., \& Ivanchenko, G. V. (2010). A Question of Balance: Time Perspective and Well-Being in British and Russian Samples. The Journal of Positive Psychology, 5, 24-40. https://doi.org/10.1080/17439760903271181

Buhrmester M. D., Kwang T., \& Gosling, S. D. (2011). Amazon's Mechanical Turk: A New Source of Inexpensive, Yet High-Quality, Data? Perspectives on Psychological Science, 6, 3-5. https://doi.org/10.1177/1745691610393980

Christie, R., \& Geis, F. L. (1970). Studies in Machiavellianism. New York: Academic Press.

Cloninger, C. R. (2004). Feeling Good: The Science of Well-Being. New York: Oxford University Press.

Cloninger, C. R. (2006). The Science of Well-Being: An Integrated Approach to Mental Health and Its Disorders. World Psychiatry, 5, 71-76.

Cloninger, C. R. (2007). Spirituality and the Science of Feeling Good. Southern Medical Journal, 100, 740-743. https://doi.org/10.1097/SMJ.0b013e318070d177

Cloninger, C. R. (2013). What Makes People Healthy, Happy, and Fulfilled in the Face of Current World Challenges? Mens Sana Monographs, 11, 16-24.

https://doi.org/10.4103/0973-1229.109288 
Cloninger, C. R., \& Zohar, A. H. (2011). Personality and the Perception of Health and Happiness. Journal of Affective Disorders, 128, 24-32. https://doi.org/10.1016/j.jad.2010.06.012

Cloninger, C. R., Salloum, I. M., \& Mezzich, J. E. (2012). The Dynamic Origins of Positive Health and Wellbeing. International Journal of Person Centered Medicine, 2, 179.

Cloninger, C. R., Svrakic, N. M., \& Svrakic, D. M. (1997). Role of Personality Self-Organization in Development of Mental Order and Disorder. Development and Psychopathology, 9, 881-906. https://doi.org/10.1017/S095457949700148X

Costa Jr., P. T., McCrae, R. R. \& Dye, D. A. (1991). Facet Scales for Agreeableness and Conscientiousness: A Revision of the NEO Personality Inventory. Personality and Individual Differences, 12, 887-898. https://doi.org/10.1016/0191-8869(91)90177-D

Drake, L., Duncan, E., Sutherland, F., Abernethy, C., \& Henry, C. (2008). Time Perspective and Correlates of Wellbeing. Time \& Society, 17, 47-61. https://doi.org/10.1177/0961463X07086304

Dunkel, C. S., \& Weber, J. L. (2010). Using Three Levels of Personality to Predict Time Perspective. Current Psychology, 29, 95-103. https://doi.org/10.1007/s12144-010-9074-x

Figueira, P., \& Bártolo-Ribeiro, R. (2013). Time Perspective Orientation and Big-Five Dimensions: An Exploratory Study in the Portuguese Population (p. 95). International Studies in Time Perspective. https://doi.org/10.14195/978-989-26-0775-7_9

Furnham, A., Richards, S. C., \& Paulhus, D. L. (2013). The Dark Triad of Personality: A 10 Year Review. Social and Personality Psychology Compass, 7, 199-216. https://doi.org/10.1111/spc3.12018

Garcia, D. (2017a). Dark Cube. In V. Zeigler-Hill, \& T. Shackelford (Eds.), Encyclopedia of Personality and Individual Differences (pp. 1-6). Cham: Springer.

https://doi.org/10.1007/978-3-319-28099-8_2302-1

Garcia, D. (2017b). Affective Profiles Model. In V. Zeigler-Hill, \& T. Shackelford (Eds.), Encyclopedia of Personality and Individual Differences (pp. 1-7). Cham: Springer. https://doi.org/10.1007/978-3-319-28099-8_2303-1

Garcia \& González (2017). The Dark Cube: Dark Character Profiles and OCEAN. Peer), 5, e3845. https://doi.org/10.7717/peerj.3845

Garcia, D., \& Lindskär, E. (2016). Regulatory Mode Profiles and the Organization of the Flow of Time. International Journal of School and Cognitive Psychology, 3, 184. https://doi.org/10.4172/2469-9837.1000184

Garcia, D., \& Rosenberg, P. (2016). The Dark Cube: Dark and Light Character Profiles. PeerJ, 4, e1675. https://doi.org/10.7717/peerj.1675

Garcia, D., Adrianson, L., Archer, T., \& Rosenberg, P. (2015). The Dark Side of the Affective Profiles: Differences and Similarities in Psychopathy, Machiavellianism, and Narcissism. Sage Open, 5, 1-14. https://doi.org/10.1177/2158244015615167

Garcia, D., MacDonald, S., \& Archer, T. (2015). Two Different Approaches to the Affective Profiles Model: Median Splits (Variable-Oriented) and Cluster Analysis (Person-Oriented). PeerJ, 3, e1380. https://doi.org/10.7717/peerj.1380

Garcia, D., Moradi, S., Amato, C., Granjard, A., \& Cloninger, K. M. (2017). Well-Being and Moral Identity. PsyCh Journal. https://doi.org/10.1002/pchj.205

Garcia, D., Sailer, U., Nima, A. A., \& Archer, T. (2016). Questions of Time and Affect: A Person's Affectivity Profile, Time Perspective, and Well-Being. PeerJ, 4, e1826. https://doi.org/10.7717/peerj.1826

Gilbert, D. (2007). Stumbling on Happiness. London: Harpercollins Publishers. 
González, F. R. (2015). La tríada oscura de la personalidad: Maquiavelismo, narcisismo y psicopatía. Una mirada evolutiva. Revista Criminalidad, 57, 253-265.

González, F. R., Nima, A. A., \& Garcia, D. (2017). Sex and Dark Times’ Strategy: The Dark Triad and Time Perspective. Psych Journal, 6, 98-99.

https://doi.org/10.1002/pchj.153

Hare, R. D. (1985). Comparison of Procedures for the Assessment of Psychopathy. Journal of Consulting and Clinical Psychology, 53, 7-16.

Humphreys, L. G. (1978). Doing Research the Hard Way: Substituting Analysis of Variance for a Problem in Correlational Analysis. Journal of Educational Psychology, 70, 873-876. https://doi.org/10.1037/0022-0663.70.6.873

Iacobucci, D., Posavac, S. S., Kardes, F. R., Schneider, M. J., \& Popovich, D. L. (2015a). Toward a More Nuanced Understanding of the Statistical Properties of a Median Split. Journal of Consumer Psychology, 25, 652-665. https://doi.org/10.1016/j.jcps.2014.12.002

Iacobucci, D., Posavac, S. S., Kardes, F. R., Schneider, M. J., \& Popovich, D. L. (2015b). The Median Split: Robust, Refined, and Revived. Journal of Consumer Psychology, 25, 690-704. https://doi.org/10.1016/j.jcps.2015.06.014

John, O. P., \& Srivastava, S. (1999). The Big Five Trait Taxonomy: History, Measurement, and Theoretical Perspectives. In L. A. Pervin, \& O. P. John (Eds.), Handbook of Personality: Theory and Research (pp. 102-138). Amsterdam: Elsevier.

Jones, D. J., \& Paulhus, D. L. (2014). Introducing the Short Dark Triad (SD3): A Brief Measure of Dark Personality Traits. Assessment, 21, 28-41.

https://doi.org/10.1177/1073191113514105

Jones, D. N., \& Paulhus, D. L. (2009). Machiavellianism. In M. R. Leary, \& R. H. Hoyle (Eds.), Handbook of Individual Differences in Social Behavior (pp. 93-108). New York, NY: Guilford.

Jones, D. N., \& Paulhus, D. L. (2011). The Role of Impulsivity in the Dark Triad of Personality. Personality and Individual Differences, 51, 679-682. https://doi.org/10.1016/j.paid.2011.04.011

Kajonius, P. J., Persson, B. N., Rosenberg, P., \& Garcia, D. (2016). The (Mis)measurement of the Dark Triad Dirty Dozen: Exploitation at the Core of the Scale. PeerJ, 4, e1748. https://doi.org/10.7717/peerj.1748

Keough, K. A., Zimbardo, P. G., \& Boyd, J. N. (1999). Who's Smoking, Drinking, and Using Drugs? Time Perspective as a Predictor of Substance Use. Basic and Applied Social Psychology, 21, 149-164. https://doi.org/10.1207/S15324834BA210207

Kowalski, C. M., Rogoza, R., Vernon, P. A., \& Schermer, J. A. (2018). The Dark Triad and the Self-Presentation Variables of Socially Desirable Responding and Self-Monitoring. Personality and Individual Differences, 120, 234-237. https://doi.org/10.1016/j.paid.2017.09.007

Lagakos, S. W. (1988). Effects of Mismodelling and Mismeasuring Explanatory Variables on Tests of Their Association with a Response Variable. Statistics in Medicine, 7, 257-274. https://doi.org/10.1002/sim.4780070126

Láng, A., \& Lenard, K. (2015). The Relation between Memories of Childhood Psychological Maltreatment and Machiavellianism. Personality and Individual Differences, 77, 81-85. https://doi.org/10.1016/j.paid.2014.12.054

MacCallum, R. C., Zhang, S., Preacher, K. J., \& Rucker, D. D. (2002). On the Practice of Dichotomization of Quantitative Variables. Psychological Methods, 7, 19-40. https://doi.org/10.1037/1082-989X.7.1.19

Morf, C. C., \& Rhodewalt, F. (2001). Expanding the Dynamic Self-Regulatory Processing 
Model of Narcissism: Research Directions for the Future. Psychological Inquiry, 12, 243-251. https://doi.org/10.1207/S15327965PLI1204_3

Paulhus, D. L., \& Williams, K. M. (2002). The Dark Triad of Personality: Narcissism, Machiavellianism, and Psychopathy. Journal of Research in Personality, 36, 556-563. https://doi.org/10.1016/S0092-6566(02)00505-6

Persson, B. N., Kajonius, P. J., \& Garcia, D. (2016). Revisiting the Structure of the Short Dark Triad under Editorial Evaluation. Assessment. https://doi.org/10.1177/1073191117701192

Pinker, S. (2011). The Better Angels of Our Nature: Why Violence Has Declined. New York, NY: Viking.

Rand, D. G. (2011). The Promise of Mechanical Turk: How Online Labor Markets can Help Theorists Run Behavioral Experiments. Journal of Theoretical Biology, 299, 172-179. https://doi.org/10.1016/j.jtbi.2011.03.004

Raskin, R., \& Hall, C. S. (1979). A Narcissistic Personality Inventory. Psychological Reports, 45, 590. https://doi.org/10.2466/pr0.1979.45.2.590

Sailer, U., Rosenberg, P., Nima, A. A., Gamble, A., Gärling, T., Archer, T., \& Garcia, D. (2014). A Happier and Less Sinister Past, a More Hedonistic and Less Fatalistic Present and a More Structured Future: Time Perspective and Well-Being. Peer), 2, e303. https://doi.org/10.7717/peerj.303

Stolarski, M., Bitner, J., \& Zimbardo, P. G. (2011). Time Perspective, Emotional Intelligence and Discounting of Delayed Awards. Time \& Society, 20, 346-363. https://doi.org/10.1177/0961463X11414296

Stolarski, M., Fieulaine, N., \& van Beek, W. (2015). Time Perspective Theory; Review, Research and Application: Essays in Honor of Philip G. Zimbardo. Berlin: Springer.

Stolarski, M., Wiberg, B., \& Osin, E. (2015). Assessing Temporal Harmony: The Issue of a Balanced Time Perspective. In Time Perspective Theory; Review, Research and Application (pp. 57-71). Berlin: Springer International Publishing. https://doi.org/10.1007/978-3-319-07368-2_3

Stolarski, M., Zajenkowski, M., \& Zajenkowska, A. (2016). Aggressive? From Time to Time... Uncovering the Complex Associations between Time Perspectives and Aggression. Current Psychology, 35, 1-10.

Vernon, P. A., Villani, V. C., Vickers, L. C., \& Harris, J. A. (2008). A Behavioral Genetic Investigation of the Dark Triad and the Big 5. Personality and Individual Differences, 44, 445-452. https://doi.org/10.1016/j.paid.2007.09.007

Vowinckel, J. C., Westerhof, G. J., Bohlmeijer, E. T., \& Webster, J. D. (2015). Flourishing in the Now: Initial Validation of a Present-Eudaimonic Time Perspective Scale. Time \& Society, 26, 203-226.

Webster, J. D. (2011). A New Measure of Time Perspective: Initial Psychometric Findings for the Balanced Time Perspective Scale (BTPS). Canadian Journal of Behavioural Science, 43, 111-118. https://doi.org/10.1037/a0022801

Zajenkowski, M., Witowska, J., Maciantowicz, O., \& Malesza, M. (2016). Vulnerable Past, Grandiose Present: The Relationship between Vulnerable and Grandiose Narcissism, Time Perspective and Personality. Personality and Individual Differences, 98, 102-106. https://doi.org/10.1016/j.paid.2016.03.092

Zimbardo, P. G., \& Boyd, J. N. (1999). Putting Time in Perspective: A Valid, Reliable Individual-Differences Metric. Journal of Personality and Social Psychology, 77, 1271-1288. https://doi.org/10.1037/0022-3514.77.6.1271 
Zimbardo, P. G., Keough, K. A., \& Boyd, J. N. (1997). Present Time Perspective as a Predictor of Risky Driving. Personality and Individual Differences, 23, 1007-1023. https://doi.org/10.1016/S0191-8869(97)00113-X

Zimbardo, P. G., Sword, R. M., \& Sword, R. K. (2012). The Time Cure: Overcoming PTSD with the New Psychology of Time Perspective Therapy. San Francisco, CA: Jossey-Bass.

Zimbardo, P., \& Boyd, J. (2008). The Time Paradox: The New Psychology of Time That Will Change Your Life. Simon and Schuster. 